\title{
Merged Department Experience at Colorado State University: How Does the Addition of an Accredited Program Influence Offerings in Horticulture
}

\author{
Harrison G. Hughes
}

\begin{abstract}
Summary. The merging of the Landscape Architecture Program (LA) with the Department of Horticulture had no effect on visibility of horticulture at Colorado State University and in the state. It did enhance the stature of the merged department as it became second only to the Department of Animal Sciences in terms of undergraduate majors and graduates in the College of Agricultural Sciences. The merger had only a limited impact on the budget. The LA is accredited. Accreditation standards aided the LA in justification of a new position. Since the merger, the Landscape Design and Contracting Program has become accredited through the Associated Landscape Contractors of America (Reston, Va.). Horticulture, which has no accrediting agency, is at a disadvantage in competing for open positions.
\end{abstract}

The Landscape Architecture Program (LA) in the Department of Recreation and Landscape Architecture of the College of Natural Resources at Colorado State University was merged with the Department of Horticulture in the College of Agricultural Sciences. Considerable debate had occurred among the affected department and college administrators, the provost and the affected faculty over the preceding 5 years as to the similarities as well as the needs of the two programs of LA and the then-named Landscape Design and Construction Concentration (LDC) in the Landscape Horticulture Major (LH) in the Department of Horticulture. These two departments in two different colleges had design as a major focus of their programs. This common element often led to confusion for entering students with interests in landscape design regarding which program best suited their needs. As part of the debate many different ideas were suggested including merging LDC into LA in the College of Natural Resources. Administrators thought that the LA program with three FTE (full-time equivalent faculty positions) and the LDC program with two FTE, if merged, would result in a stronger program and reduce problems with confusion by students. Since plant materials, required by both programs at the time, were the horticulture, it seemed logical that LA be merged with horticulture. The merger with the Department of Horticulture occurred, but the two programs (LA and LDC) remained distinct.

\footnotetext{
Department of Horticulture and Landscape Architecture, Colorado State University, Fort Collins, CO 80523. 
Table 1. Number of undergraduates in horticulture, landscape horticulture, and landscape architecture completing their undergraduate degrees in each of the years from 1990-2000.

\begin{tabular}{lccr}
\hline Calendar year & Landscape horticulture & Horticulture & Landscape architecture \\
\hline 1990 & $29(13)^{\mathrm{y}}$ & 5 & 12 \\
1991 & $13(3)$ & 5 & 7 \\
$1992^{\mathrm{z}}$ & $25(16)$ & 5 & 25 \\
1993 & $28(14)$ & 6 & 16 \\
1994 & $30(16)$ & 8 & 18 \\
1995 & $30(10)$ & 9 & 16 \\
1996 & $18(10)$ & 2 & 15 \\
1997 & $33(16)$ & 12 & 13 \\
1998 & $59(35)$ & 23 & 12 \\
1999 & $42(20)$ & 12 & 18 \\
2000 & $47(17)$ & 20 & 17 \\
\hline
\end{tabular}

${ }^{\mathrm{z}}$ Horticulture and landscape architecture were merged in Fall 1992.

y Numbers in parentheses indicate the students in landscape design construction (contracting) that were graduating within the landscape horticulture major.

The distinct, but joined programs are part of the now renamed Department of Horticulture and Landscape Architecture which contains the three majors: LA, LH (with three concentrations including LDC), and horticulture $[(\mathrm{H})$ with 4 concentrations]. In the first full year with LA the department had 189 undergraduate majors in $\mathrm{H}+\mathrm{LH}$ and 109 in LA and pre-LA. There were a total of 34 undergraduates in $\mathrm{H}+\mathrm{LH}$ and 16 in LA completing their degrees. The department was then and now second only to the Department of Animal Sciences in the College of Agricultural Sciences in terms of majors and graduates of the undergraduate programs. This size enhanced departmental status and overall visibility in the college and university. However, confusion by students, high school counselors and university administrators remained regarding differences between the LA and LDC programs.

The merger resulted in the addition of 3 FTE LA faculty to a department having about 11 FTE on-campus horticulture faculty and eight FTE off-campus faculty. These differences in numbers led to some concerns on the part of the LA faculty, especially since the two FTE LDC faculty had been a part of the original horticulture faculty for many years. Concerns as to the degree of understanding of the creative works as related to tenure and advancement were most apparent. Also, competition for students between the LA and LDC programs was evident. Furthermore, there was concern that the transfer of LA was not accompanied by the addition of sufficient funds to cover departmental support functions.

The concerns of joining two programs (LA and LDC) with some similarities generated increased discussion among involved administrators and faculty about issues of overlap and legitimacy. These problems have been overcome in part by a refocusing of LDC with greater emphasis on contracting, highlighting the differences between the two. For example, the name was changed from Landscape Design and Construction to Landscape Design and Contracting. The name change and the fact that LA was accredited stimulated the LDC faculty to apply for accreditation through the Associated Landscape Contractors of America. Accreditation was received in 1998. Stronger ties to the landscape contracting industry in the state and nation now exist as a result of the accreditation stimulated in part by joining LA and $\mathrm{H}$.

A comparison of student enrollments and number of undergraduates completing their degrees in the three majors over a 10 -year period just before and since the merger is interesting. During this time the number of majors and those graduating (Table 1 ) has increased although at somewhat different rates among the programs. In 1990 , there were 34 graduating in $\mathrm{H}+\mathrm{LH}$ and 12 in LA. Over the 10 -year period the number of graduates increased to 67 in Spring 2000 in $\mathrm{H}+\mathrm{LH}$ and 17 in LA. However, the relative numbers per FTE remained approximately the same in LA but substantially increased in $\mathrm{H}+\mathrm{LH}$. This in part has been due to accreditation standards that recommend specific student/faculty ratios for LA. The accrediting standards aided the department in obtaining a new LA position in 1996 for a total of four FTEs in the LA program. The desired student/faculty ratio is still far above desired standards in the LA profession though. Similarly, the accrediting team for the Associated Landscape Contractors of America recommended

Table 2. Total courses taught and credit hour production in the horticulture $(\mathbf{H})$ plus landscape horticulture (LH) majors and landscape architecture (LA) majors in each of three academic years.

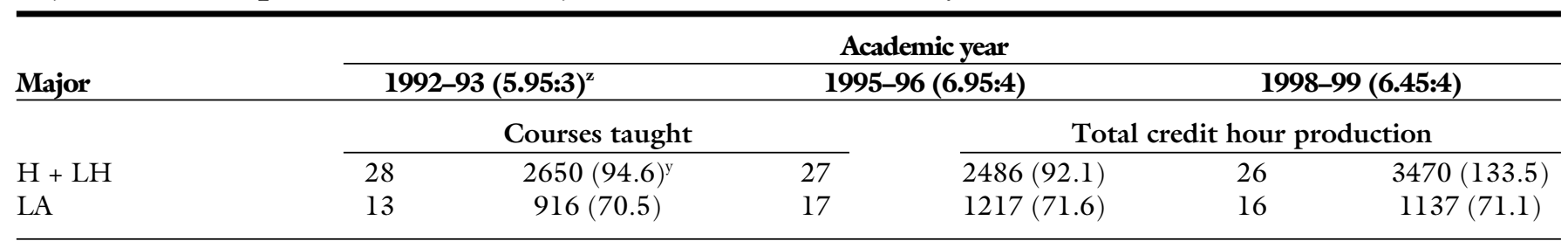

${ }^{\mathrm{z}}$ Numbers in parentheses indicate full time equivalent faculty in horticulture plus landscape horticulture and landscape architecture, respectively.

${ }^{y}$ Numbers in parentheses indicate credit hour production per course. 
Table 3. Number of courses taught and credit hour production per full time equivalent faculty (FTE) in horticulture (H) plus landscape horticulture (LH) and landscape architecture (LA) majors in each of 3 academic years.

\begin{tabular}{|c|c|c|c|c|c|c|}
\hline \multirow[b]{2}{*}{ Major } & \multicolumn{6}{|c|}{ Academic year } \\
\hline & \multicolumn{2}{|c|}{ 1992-93 } & \multicolumn{2}{|c|}{ 1995-96 } & \multicolumn{2}{|c|}{ 1998-99 } \\
\hline & \multicolumn{3}{|c|}{ Courses taught per FTE } & \multicolumn{3}{|c|}{ Credit hour production per FTE } \\
\hline LA & 4.3 & 305.3 & 4.3 & 304.3 & 4.0 & 284.3 \\
\hline
\end{tabular}

that an additional LDC faculty member be hired. Unfortunately, funding at this time is not available.

A comparison of number of courses taught and credit hour production by LA as related to the other faculty is also interesting. Of course there is difficulty in making such direct comparisons, as studio classes, for instance, are restricted as to size due to the need for drafting equipment and individual faculty student interaction. Accreditation standards also recommend lower faculty/student ratios than traditionally is present in horticulture classes. Current levels are 20 students per class at the sophomore and above level of class in LA. LDC faculty have a comparable limit of 22 . In academic year 1992-93, faculty in $\mathrm{H}+\mathrm{LH}$ taught 28 courses with a total credit hour production of 2650 while LA faculty taught a total of 13 courses with a total of 916 (Table 2). Credit hour production for this purpose is defined as one credit assigned per student per hour per week in lecture. Laboratories and studios are considered as one credit hour production per two hours in class per week. For pur- poses of this analysis, laboratories taught by teaching assistants were not averaged in. Type B courses such as internships, independent studies, practicums or graduate research credit were not averaged in as well. Type A courses per FTE taught by $\mathrm{H}+\mathrm{LH}$ faculty were 4.7 with a credit hour production of each faculty of 445 , while LA faculty taught 4.3 courses with a credit hour production of 305 per FTE (Table 3 ). More recently, in the 1998-99 academic year, $\mathrm{H}+\mathrm{LH}$ faculty have been teaching loads of four courses per FTE but with a substantial increase in credit hour production of 538 , while LA faculty have a similar load of four courses but with a credit hour production of 285 per FTE, similar to the 1992-93 academic year. Once again, direct comparisons are difficult to make due to the high degree of faculty/student interaction required of studio classes and accreditation requirements in LA. There has been no impact on research and extension programs in horticulture.

Accreditation of LA, and now LDC, has placed specific constraints on the department. The horticulture program has no accrediting authority and therefore does not have this leverage should limited resources place constraints on how the department allocates vacant positions and general funding. Our clientele and periodic reviews do support horticulture programs, but student demand and numbers often take precedence. Recently, we experienced a reallocation within the university towards specific priorities. As a result, a major and a nonmajor course in horticulture were lost, as well as a graduate laboratory course. So, that and the retirement of our last faculty on-campus with vegetable crop expertise (with no replacement) have already created a demand for instructors for specific horticulture areas for which faculty expertise is lacking. To meet some of these demands we are considering the use of off-campus faculty with specific expertise to meet these needs. Should funds become available for additional positions, the horticulture program would be at an apparent disadvantage without accreditation. Perhaps it is time for the American Society for Horticultural Science to revisit accreditation. 